\title{
Fractality in the Utilization of Internet in the World
}

\author{
Helen B. Boholano \\ Cebu Normal University, Cebu City, Philippines \\ Email: hibihag08@gmail.com
}

Received 29 November 2013; revised 30 December 2013; accepted 10 January 2014

Copyright (C) 2014 by author and Scientific Research Publishing Inc.

This work is licensed under the Creative Commons Attribution International License (CC BY). http://creativecommons.org/licenses/by/4.0/

(c) (i) Open Access

\section{Abstract}

This paper sought to describe the roughness of the penetration of the use of internet to the population of the world from Worldbank and Internet World Stats. The Internet as one of the growing technology is one of the best channels for people seeking knowledge, fun, and friends. Information and Communication Technology (ICT) has played an educational role in formal and non-formal settings, in programs provided by governmental agencies, public and private educational institutions, for-profit corporations and non-profit groups, and secular and religious communities as reported by UNESCO. Fractal features and analysis were used in this study in additional texture parameters. Results revealed that China is the No. 1 internet user in the world. Internet is utilized in China in business, education, government sectors, work places and other agencies or institutions. The internet is described as the single most important invention of the $21^{\text {st }}$ century and as an equalizer that facilitates access to information and resources. Furthermore, a single or mono fractal, "ideal" fractal dimensionality was detected in the utilization of internet in the world.

\section{Keywords}

Fractality; Internet Utilization; Roughness

\section{Introduction}

The Internet quickly entered the life of the humankind since $20^{\text {th }}$ century. It took more than ten $(10)$ years and several processes before people face the fact of its spreading all over the world, including the developing countries. It has become not only the hugest information resource in the world, but-what is even more important - the most rapid means of communication [1].

People around the world have got an opportunity to communicate with each other in quite a short time through the internet. In comparison with a snail-mail or even airmail, e-mail gets over distance and time, fron- 
tiers of the states with a lightning speed. The comparatively rapid embracement of information and communication technologies (ICTs) by educational institutions has transformed approaches to teaching and learning, has modified the way information is presented to learners and has changed the ways teachers and institutions communicate with students, students communicate with teachers, the institution and each other [2].

Internet users increased each year in school, work places and even out of school individual. The number of internet users grew by 114 percent when compared with the figure in 2000 [3]. Chan and Fang (2007) as cited from Burns (2006) forecasted that the adoption of various information technologies, including Wi-Fi connectivity, RSS feeds, blog authoring and podcasts, will drive internet usage worldwide. New communication technologies including the internet have greater impacts on the lives of young people than all other technological innovations [3].

This paper sought to investigate the ruggedness of the data through fractal analysis of the top 20 countries in the World per the 2012 data according to the Worldbank and Internet World Stats. The ranking is based on the population and its penetration to people and internet users' percentage per country. Fractal dimension was computed to quantify complexity of shape in relation to the structure and texture. It also indicates the degree of self-similarity and scale invariance.

\section{Short Literature Review}

In the study of Chan and Fang (2007), the uses and gratifications theory proposed by Blumler and Katz (1974) predicts that young people will select and use the media to best fulfil their individual needs. Now with the increasing penetration of internet in Hong Kong, it is time to update the knowledge about how this new media may affect young people's allocation of time spent with various media, as well as how the internet can be used to fulfill various communication needs [3].

Internet is perceived to be very important to people and its convenience to communicate others around the world. There has been a huge explosion in the adoption and use of the internet worldwide. It has been major influences on the way we work, shop, make payments, travel, socialize and IT has digitalized our world. With the rapid diffusion of Internet technologies, China has emerged as the country with the largest Internet population, making it a leading player in the Internet market [4]. In addition, Lai and Ming-To (2007), mention the use of Internet technologies as the dominant channel for communication, collaboration, and commerce in China is imminent. Chan and Fang (2007) as cited from Arnett (1995), cites young people make active choices of the media they use according to their personalities, socialization needs, and personal identification needs. In terms of the Internet penetration rate, the percentage of citizen uses the Internet in each province - these four coastal regions ranked third, fourth, eighth, and 11th in China, respectively, in 2010, with penetration rates ranging from 35 to 55 percent [4].

As Internet access increases and consumer demand for online health services and information grows there is an urgent need for information about whether this causes more harm than good [5]. In 1998, Hoffman and Novak revealed that almost 70 percent of the schools in this country have at least one computer connected to the Internet, less than 15 percent of classrooms have Internet access. In spite of the infrastructure problems in the Philippines, educators, students, government workers and common people make use of internet in daily activities.

The new digital ICTs are not single technologies but combinations of hardware, software, media, and delivery systems [6]. ICT is also utilized by different school whether public or private from basic education to higher education. In the report of UNESCO by Blurton (1999), stressed that in the United States, the ratio of students per computer dropped from 63:1 to 6:1 from 1985 to 1997 (Market Data Retrieval, 1998) while the number of schools with internet access has grown from 35\% in 1994 (U.S. National Center for Education Statistics, 1996) to $72 \%$ in 1997 (QED's Educational Technology Trends, 1997).

\section{Methodology}

Several studies mentioned that fractals have found widespread application in a range of scientific fields, including education [7]. A great number of physical systems tend to present similar behaviours on different scales of observation [8]. In the 1960s, the mathematician Benoit Mandelbrot used the adjective "fractal" to indicate objects whose complex geometry cannot be characterized by an integral dimension. 
The attribute variation in a fractal object can be described through fractal dimension, which is a measure of the roughness, or fragmentation, of the object. More jagged-looking objects have larger fractal dimensions. It is said that the higher the fractal dimension is, the more squiggly the object that is inside the square. A multifractal structure can be considered as a superposition of homogeneous monofractal structures [9].

In this study, the researcher utilized data from Worldbank and Internet World Stats. To determine the fractal dimension of the tabulated data set, the researchers first look at the entire ruggedness index $(\lambda)$ then assess the ruggedness of the data at each scale (s) by looking at $\lambda$ s. Furthermore, these formulas were used:

Legendre' Spectrum

$$
\begin{gathered}
\text { Lamba }=1-\frac{\operatorname{loge}(1-\text { alpha })}{\operatorname{loge}(\text { data } / \text { min of data })} \\
\text { Lamba }=1-\frac{\operatorname{loge}(1-\text { alpha })}{\operatorname{loge}(\text { data })} \\
\text { Scale }=s=1 / \operatorname{loge}(\text { data } / \mathrm{min})
\end{gathered}
$$

\section{Results and Discussion}

This (Table 1) shows the utilization of internet all over the world. This finding suggests that substantially more Chinese citizens will be going online in the next few years. According to the 27th Statistical Report on Internet Development in China, search engines were the top application of Internet users in 2010, surpassing Web music, the top application for the previous three years [9]. Blurton, (1999) as cited from Jensen (1998), reported that a number of international infrastructure building initiatives are underway on the continent including the United Nations Secretary General's program me Harnessing Information Technology for Development that will substantially improve the Internet infrastructure by the year 2000. Furthermore, government services were improved through the use technology.

Table 1. Ranking of the internet users in the World.

\begin{tabular}{cccccc}
\hline Rank & Country & Population & Internet users & Penetration (\%Population) & Users (\%World) \\
\hline $\mathbf{1}$ & China & $1,343,239,923$ & $538,000,000$ & $40.10 \%$ & $22.40 \%$ \\
$\mathbf{2}$ & United States & $313,847,465$ & $245,203,319$ & $78.10 \%$ & $10.20 \%$ \\
$\mathbf{3}$ & India & $1,205,073,612$ & $137,000,000$ & $11.40 \%$ & $5.70 \%$ \\
$\mathbf{4}$ & Japan & $127,368,088$ & $101,228,736$ & $79.50 \%$ & $4.20 \%$ \\
$\mathbf{5}$ & Brazil & $193,946,886$ & $88,494,756$ & $45.60 \%$ & $3.70 \%$ \\
$\mathbf{6}$ & Russia & $142,517,670$ & $67,982,547$ & $47.70 \%$ & $2.80 \%$ \\
$\mathbf{7}$ & Germany & $81,305,856$ & $67,483,860$ & $83.00 \%$ & $2.80 \%$ \\
$\mathbf{8}$ & Indonesia & $248,645,008$ & $55,000,000$ & $22.10 \%$ & $2.30 \%$ \\
$\mathbf{9}$ & United Kingdom & $63,047,162$ & $52,731,209$ & $83.60 \%$ & $2.20 \%$ \\
$\mathbf{1 0}$ & France & $65,630,692$ & $52,228,905$ & $79.60 \%$ & $2.20 \%$ \\
$\mathbf{1 1}$ & Nigeria & $170,123,740$ & $48,366,179$ & $28.40 \%$ & $2.00 \%$ \\
$\mathbf{1 2}$ & Mexico & $114,975,406$ & $42,000,000$ & $36.50 \%$ & $1.70 \%$ \\
$\mathbf{1 3}$ & Iran & $78,868,711$ & $42,000,000$ & $53.30 \%$ & $1.70 \%$ \\
$\mathbf{1 4}$ & Korea & $48,860,500$ & $40,329,660$ & $82.50 \%$ & $1.70 \%$ \\
$\mathbf{1 5}$ & Turkey & $79,749,461$ & $36,455,000$ & $45.70 \%$ & $1.50 \%$ \\
$\mathbf{1 6}$ & Italy & $61,261,254$ & $35,800,000$ & $58.40 \%$ & $1.50 \%$ \\
$\mathbf{1 7}$ & Philippines & $103,775,002$ & $33,600,000$ & $32.40 \%$ & $1.40 \%$ \\
$\mathbf{1 8}$ & Spain & $47,042,984$ & $31,606,233$ & $67.20 \%$ & $1.30 \%$ \\
$\mathbf{1 9}$ & Vietnam & $91,519,289$ & $31,034,900$ & $33.90 \%$ & $1.30 \%$ \\
$\mathbf{2 0}$ & Egypt & $83,688,164$ & $29,809,724$ & $35.60 \%$ & $1.20 \%$ \\
\hline
\end{tabular}

Source: Internet World Stats. http://www.internetworldstats.com/stats.htm. 
Figure 1 shows the monofractality of the use of internet in the world. It is noted that there are more internet users in China, United States and India. With Internet use increasing in other developed countries, it is used in China in education, e-commerce, banking and gaming. Several studies conducted and examined cross-country differences in Internet penetration in 1999-2001, and find that they are associated with income per capita, the dependency ratio, electricity consumption and regulatory quality [8]. In US there are more users of Web while there is a gap between Americans and Egyptians becomes proportionally larger.

Figure 2 shows a linear fractal has a strong self-similarity and appears identical at varying scales. Fractals have a wide range of applications including signal and image compression as well as in seismology. They are also applied in digital sundial and in computer and video game design. It is noticeable that users used the Web at locations other than home, school or work, regardless of whether there is a computer at home.

Figure 3 showed the probability distribution in terms of the penetration of internet use in the world. There are more users whose penetration is 0 - 10 than 10 - 20. The number of Internet users is based on reported estimates of users, derivations from reported Internet Access Provider (ISP) subscriber counts, or calculated by multiplying the number of Internet hosts by an estimated multiplier. Thus, Internet use may be understated, particularly in developing countries where many commercial subscribers rent computers connected to the Internet [9]. Access to a personal computer, whether at home, work, school or somewhere else, is important because it is currently the dominant mechanism by which individuals gain access to the Internet [10].

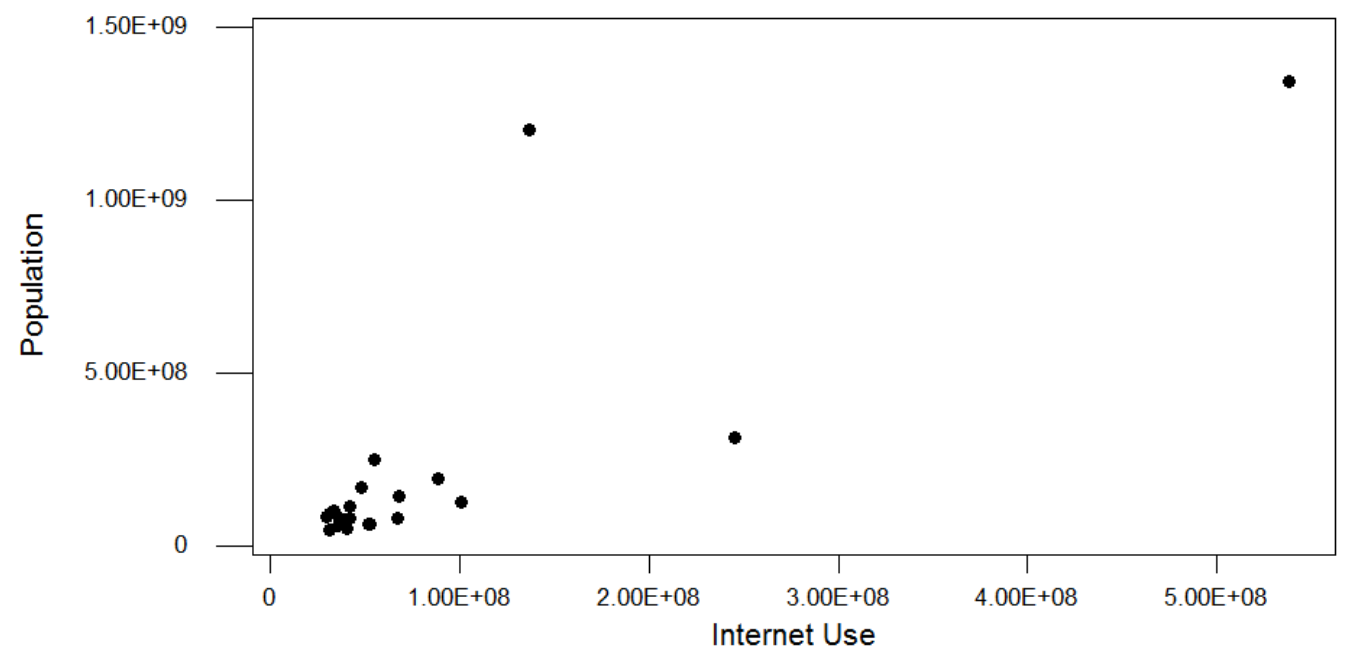

Figure 1. The use of internet in the World.

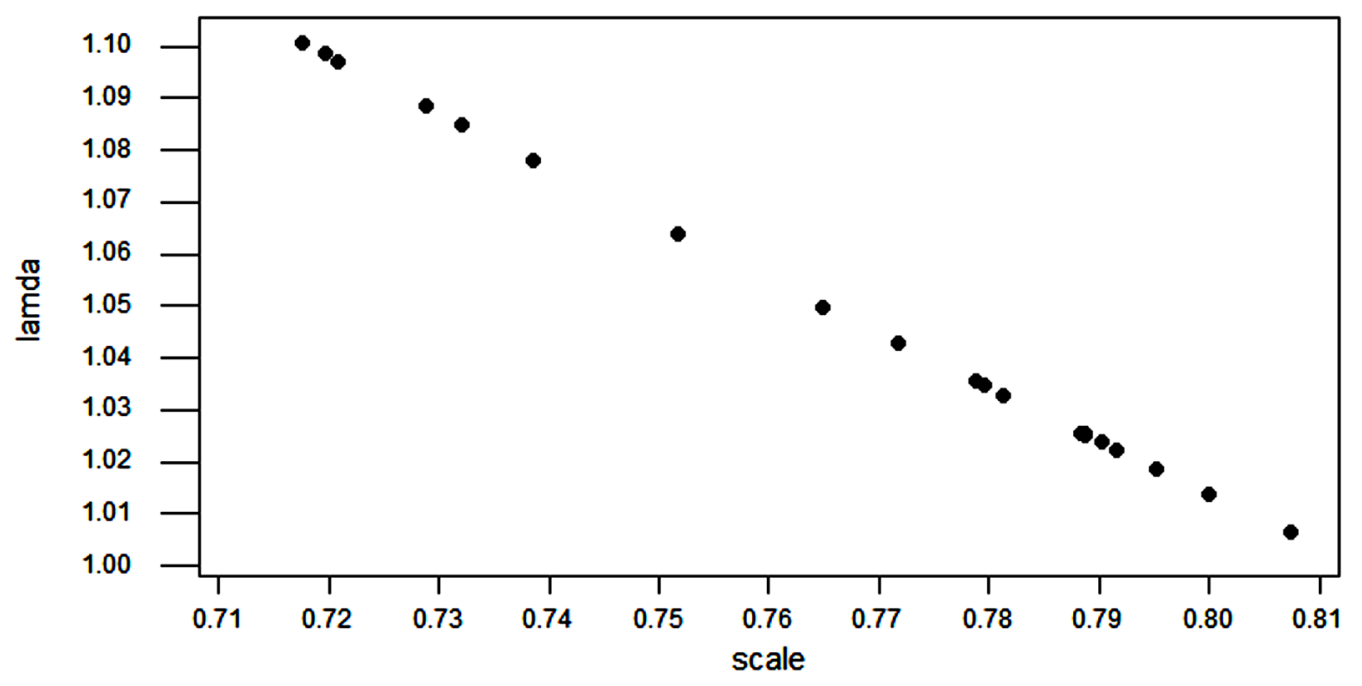

Figure 2. The use of internet in the world by population. 


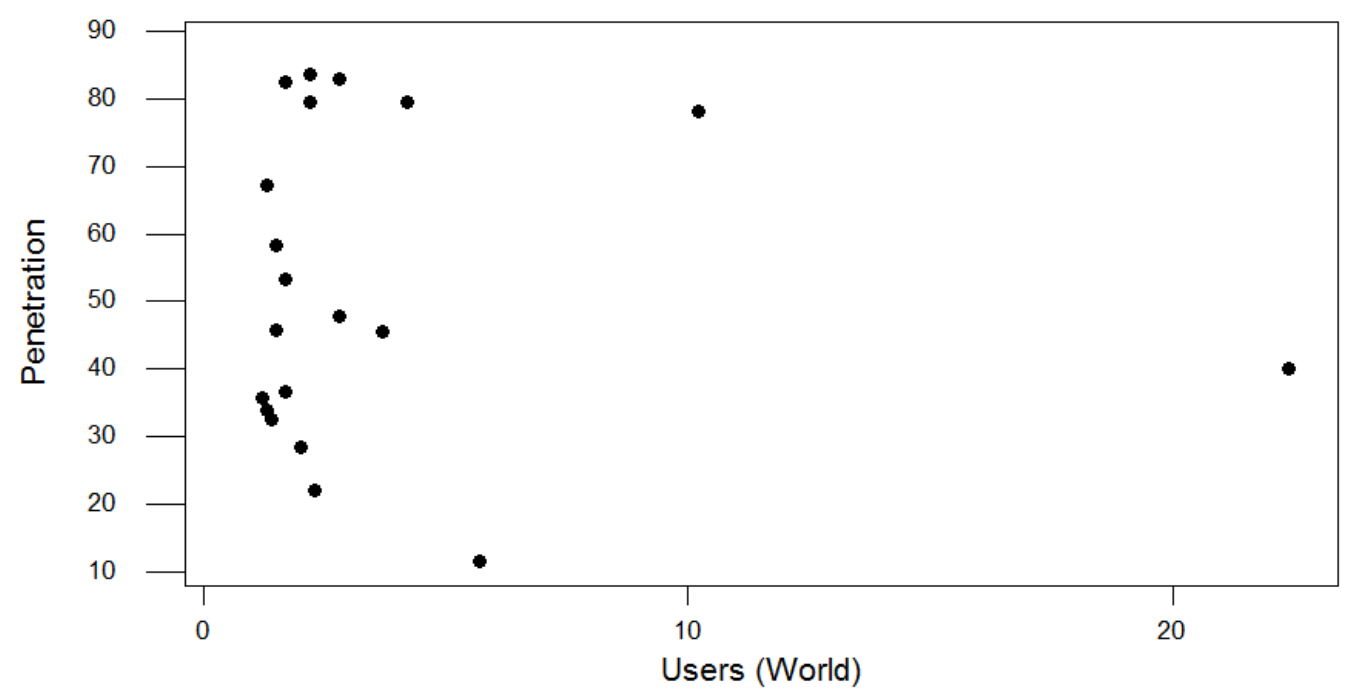

Figure 3. The penetration of internet by population.

\section{Conclusion}

Computer and Internet penetration rates analyzed were derived from the number of people and Internet users around the world. Computer and Internet penetration rates for the top 20 countries were analyzed using fractal analysis. Fractal dimension is a powerful tool in determining the ruggedness of the data. It also determines whether mono or multi fractals. Technology use has increased rapidly among several developing countries. China, United States, India, Japan and Mexico were the top 5 internet users in the world. The study revealed that China is the top internet user in the world. There are more internet users whose penetration is $0-10$ than $10-20$. This implies that internet is a productivity tool for progress. As identified by the top 20 internet users in the world services will be improved through the use of technology.

\section{References}

[1] UNESCO (2003) Internet in Education. http://iite.unesco.org/pics/publications/en/files/3214612.pdf

[2] Clayton, J. (2007) Educational Levels of Internet Use. Proceedings of Ascilite Singapore 2007, Waikato Institute of Technology.

[3] Chan, K. and Fang, W. (2007) Use of the Internet and Traditional Media among Young People. www.emeraldinsight.com/reprints

[4] Lai, L. and Ming-To, W. (2007) The Emergence of China in the Internet Market.

[5] Bessell, et al. (2001) Do Internet Interventions for Consumers Cause More Harm than Good? A Systematic Review. Blackwell Science Ltd. 2002 Health Expectations.

[6] Blurton, C. (1999) New Directions of ICT-Use in Education.

[7] Boholano, H., Olvido, M. and Cardillo, M. (2013) Fractal Variations of Research and Teaching in Top Ranking Universities in Asia and the World.

[8] Chinn, M. and Fairlie, R. (2006) ICT Use in the Developing World: An Analysis of Differences in Computer and Internet Penetration. Review of International Economics, 18, 153-167.

[9] Lopes, R. and Betrouni, N. (2009) Fractal and Multifractal Analysis: A Review.

[10] Hoffman, D.L. and Novak, T.P. (1998) Bridging the Racial Divide on the Internet. Science, 280, 390-391. 